\title{
Nanoscale
}

Check for updates

Cite this: Nanoscale, 2019, 11, 7317

\section{Real time optical observation and control of atomically thin transition metal dichalcogenide synthesis $\uparrow$}

\author{
Hamid Reza Rasouli, ${ }^{a}$ Naveed Mehmood, ${ }^{a}$ Onur Çakıroğlu ${ }^{b}$ and \\ T. Serkan Kasırga (iD *a,b
}

\begin{abstract}
Understanding the mechanisms involved in chemical vapour deposition (CVD) synthesis of atomically thin transition metal dichalcogenides (TMDCs) requires precise control of numerous growth parameters. All the proposed mechanisms and their relationship with the growth conditions are inferred from characterising intermediate formations obtained by stopping the growth blindly. To fully understand the reaction routes that lead to the monolayer formation, real time observation and control of the growth are needed. Here, we demonstrate how a custom-made CVD chamber that allows real time optical monitoring can be employed to study the reaction routes that are critical to the production of the desired layered thin crystals in salt assisted TMDC synthesis. Our real time observations reveal the reaction between the salt and the metallic precursor to form intermediate compounds which lead to the layered crystal formation. We identified that both the vapour-solid-solid and vapour-liquid-solid growth routes are in an interplay. Furthermore, we demonstrate the role $\mathrm{H}_{2}$ plays in the salt-assisted WSe $\mathrm{W}_{2}$ synthesis. Finally, we observed the synthesis of the $\mathrm{MoSe}_{2} / \mathrm{WSe}_{2}$ heterostructures optically, and elucidated the conditions required for both lateral and vertical heterostructure syntheses.
\end{abstract}

Received 21st January 2019,

Accepted 17th March 2019

DOI: $10.1039 /$ c9nr00614a

rsc.li/nanoscale
There are two growth modes in CVD synthesis of TMDCs. (1) Vapour-Solid-Solid (VSS): Vaporized precursors are adsorbed on the substrate and form crystals via surface diffusion and bond formation at an elevated temperature, ${ }^{10}$ and (2) Vapour-Liquid-Solid (VLS): Supersaturated liquid droplets containing the constituent elements form the crystals. ${ }^{11}$ Fig. 1(a) depicts these growth modes. Despite many studies on the CVD growth mechanisms of few layer TMDCs, it is unclear which growth mode prevails under different growth conditions. The greatest challenge in understanding the on-going processes during the growth is the inaccessibility of the tube furnace for real time observations. To analyse the intermediate products leading to the desired crystal growth, these products must be captured by shutting off the furnace and quenching the synthesis by a rapid cool down. Although there are reports on real time visual observation of graphene, ${ }^{12-14} \mathrm{Y}_{2} \mathrm{BaCuO}_{5}$ and $^{15}$ vanadium dioxide nanocrystal ${ }^{16}$ synthesis, due to the complexity of the growth process no such observations have been made for TMDCs.

To explore the synthesis of atomically thin TMDCs, we built a custom-made CVD chamber that allows real time optical observation and control of multi-precursor crystal growth. Fig. 1(b) shows a schematic of the chamber. Our investigations of the CVD growth mechanisms of atomically thin TMDCs rest on the ability to control four separate alumina heaters while
${ }^{a}$ UNAM - Institute of Materials Science and Nanotechnology,
Ankara 06800, Turkey. E-mail: kasirga@unam.bilkent.edu.tr

${ }^{b}$ Department of Physics, Bilkent University, Ankara 06800, Turkey

$\dagger$ Electronic supplementary information (ESI) available. See DOI: 10.1039/ c9nr00614a 

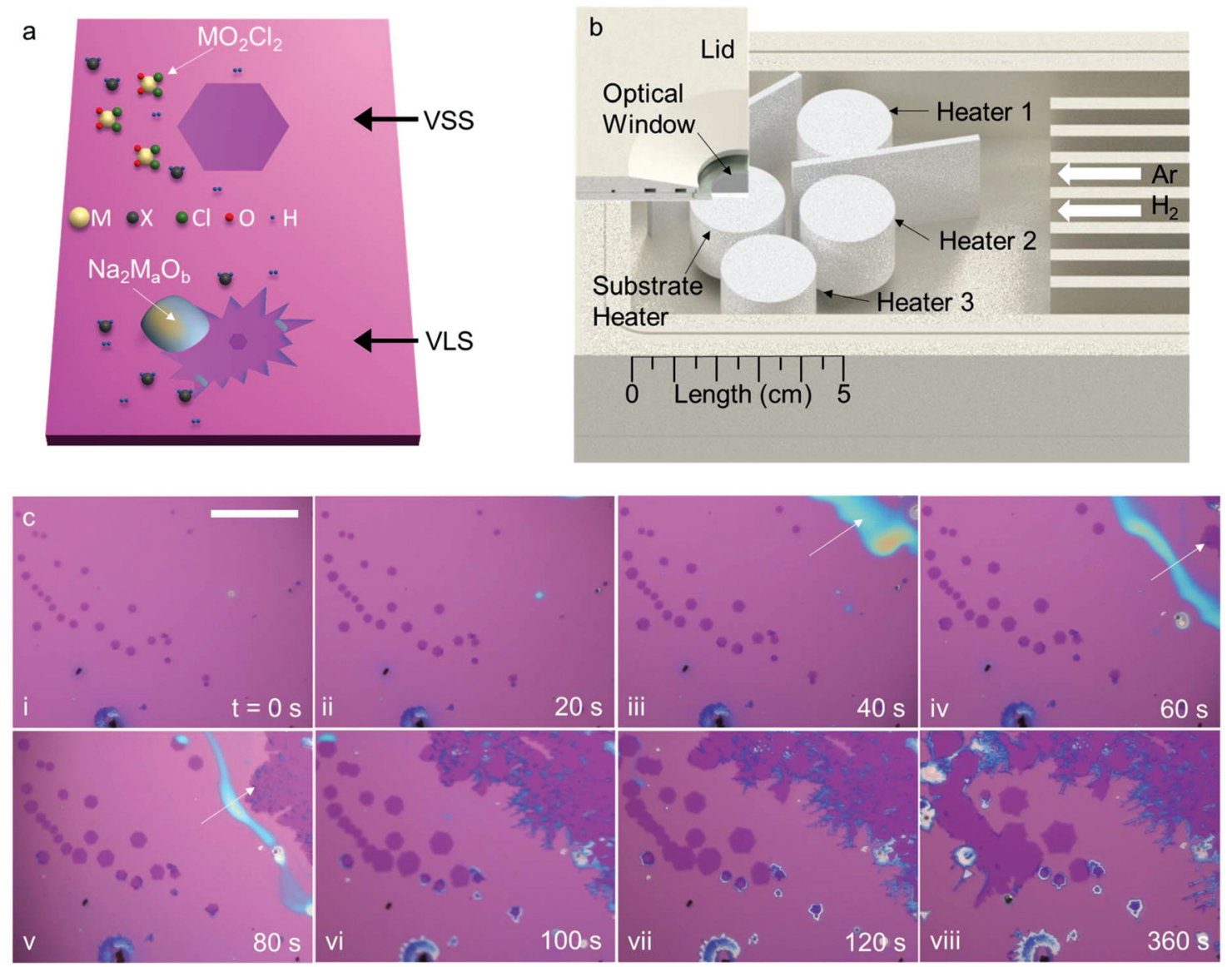

Fig. 1 Schematic of the CVD growth modes, custom-made CVD chamber, and an exemplary growth. (a) Depictions of VSS and VLS growth modes for $\mathrm{NaCl}$ assisted TMDC synthesis. In the VSS mode, adsorbed vapour forms the crystals while in the VLS mode, a liquid precursor forms the crystal via a chemical reaction. $M$ and $X$ denote the metal and the chalcogen precursors, respectively. (b) Schematic of the custom-made CVD chamber depicts the configuration of the heaters, relevant lengths and the quarter cross-section of the upper lid. Ar and $\mathrm{H}_{2}$ flow is indicated by the white arrows. Heater 1 is separated from the rest of the reactors to prevent heating of the chalcogen precursor by radiation from the precursor heaters. (c) Real time optical micrographs captured during a synthesis is given in (i-viii). The substrate temperature is at $790{ }^{\circ} \mathrm{C}$ and the series of pictures show the evolution of atomically thin WSe $\mathrm{W}_{2}$ crystals. Time $t=0 \mathrm{~s}$ marks the beginning of our observation of the particular region captured in the images. Hexagonal monolayers grow larger as time goes on with a rate of $\sim 0.2 \mu \mathrm{m} \mathrm{s}^{-1}$. White arrow in (iii) attracts attention to the liquid that promotes the synthesis of the monolayers. As time goes on the amount of liquid diminishes and irregularly shaped WSe $\mathrm{Crystals}_{2}$ form. After 6 minutes (viii) from the beginning of the observation, no liquid is left, and the lateral growth of the crystals stops. Scale bar is $100 \mu \mathrm{m}$.

monitoring the growth substrate under an optical microscope. This ability allows the chamber to be used as a multi-zone chamber. One heater dedicated for the growth substrate is directly located under a $0.5 \mathrm{~mm}$ thick sapphire window for optical observations. A $40 \times$ ultra-long working distance $(4.4 \mathrm{~mm})$ objective is employed to have a high resolving power while maintaining a large enough hot zone above the substrate. The other heaters are dedicated for the growth precursors and their separation to the substrate heater can be adjusted within the chamber (see the ESI $\uparrow$ for details).

We focus on salt assisted synthesis of $\mathrm{WSe}_{2}$ monolayers on an oxidised Si chip as a demonstration of the versatility of our chamber. Fig. 1(c) shows a series of optical images obtained during the synthesis at $790{ }^{\circ} \mathrm{C}$ (see ESI Movie $1 \dagger$ ). $\mathrm{WSe}_{2}$ crystal formation via VSS and VLS modes can be observed in real time. Fine mesh grains of $\mathrm{WO}_{3}$ and $\mathrm{NaCl}$ are placed on heater 2 and Se on heater 1 . The substrate heater and heater 2 temperatures are increased simultaneously. When they reach $600{ }^{\circ} \mathrm{C}$, the temperature of heater 1 is brought to $300^{\circ} \mathrm{C}$, above the melting point of Se. At the same time $\mathrm{H}_{2}$ is introduced to aid the growth of the monolayers. We use atomic force microscopy (AFM), Raman and photoluminescence (PL) intensity maps to characterize the samples. Photoluminescence (PL) maps obtained from typical VSS crystals show that they are high quality WSe 2 monolayers (ESI Fig. S5 and S6 †). ${ }^{17}$

To understand the possible crystal formation routes, we placed a $250 \mu^{3}$ large grain of $\mathrm{NaCl}$ surrounded by smaller grains of $\mathrm{WO}_{3}$ on a $\mathrm{SiO}_{2} / \mathrm{Si}$ chip on the substrate heater and observed the dynamics of the intermediate compound formation before $\mathrm{WSe}_{2}$ growth. Optical images captured during the heat up show the intermediate stages of the reaction between $\mathrm{WO}_{3}$ and $\mathrm{NaCl}$ (Fig. 2(a)-(f)). Firstly, we observe a turquoise liquid formation in the vicinity of the $\mathrm{WO}_{3}$ particles at as low as $600{ }^{\circ} \mathrm{C}$. This is consistent with the previously 

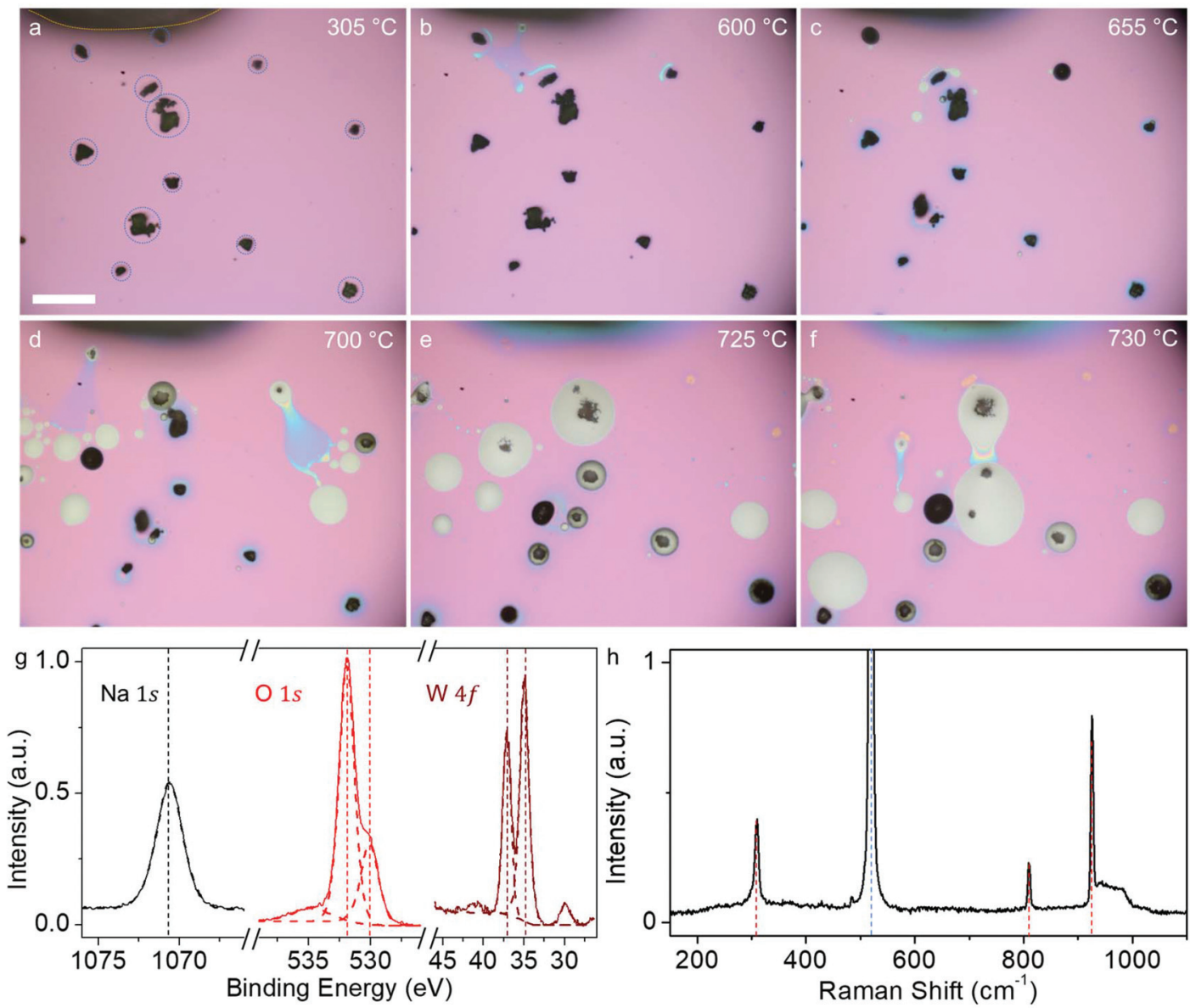

Fig. 2 Formation and characterization of the intermediate compound. (a-f) Optical micrographs obtained during the synthesis at various temperatures. Yellow dashed line at the top in (a) indicates the edge of the salt particle and grains encircled by blue dashed lines are $\mathrm{WO}_{3}$ particles. As the temperature increases first a turquoise liquid forms around the $\mathrm{WO}_{3}$ grains. Then, as time goes on the liquid droplet enlarges by consuming the WO grains. Scale bar is $100 \mu \mathrm{m}$. (g) XPS survey shows that the liquid is composed of $\mathrm{Na}, \mathrm{O}$ and $\mathrm{W}$. The $\mathrm{Na}$ 1s survey can be fitted with a single peak at $1070.6 \mathrm{eV}$ that can be attributed to $\mathrm{Na}$ in $\mathrm{Na}_{2} \mathrm{WO}_{4}$. O 1s binding energy can be fitted with two peaks, one at $532.9 \mathrm{eV}$ and the other at $530.2 \mathrm{eV}$ that can be attributed to the substrate and $\mathrm{Na}_{2} \mathrm{WO}_{4}$, respectively. W $4 \mathrm{f}^{5 / 2}$ and $4 \mathrm{f}^{7 / 2}$ peaks located at 37.3 and 34.9 eV corresponds to the previously reported values ${ }^{18,19}$ for $\mathrm{W} 4 \mathrm{f}$ of $\mathrm{Na}_{2} \mathrm{WO}_{4}$ in the literature. The peak at $30.1 \mathrm{eV}$ can be attributed to Na $2 \mathrm{p}$. (h) The Raman spectrum obtained from a solidified intermediate compound. Peaks marked with red dashed lines correspond to the Raman modes of $\mathrm{Na}_{2} \mathrm{WO}_{4}$ and the blue dashed line marks the $520 \mathrm{~cm}^{-1}$ Si peak from the substrate.

reported thermogravimetry and differential scanning calorimetry measurements on $\mathrm{NaCl}-\mathrm{WO}_{3}$ mixtures. ${ }^{9}$ At this early stage, when we stop the synthesis and perform scanning electron microscopy (SEM) imaging and energy dispersive X-ray spectroscopy (EDX) mapping, $\mathrm{Na}$ and $\mathrm{Cl}$ on the $\mathrm{WO}_{3}$ grains are detected (see Fig. S8 in the ESI†). This clearly indicates that $\mathrm{NaCl}$ sublimates and condenses on $\mathrm{WO}_{3}$. At higher substrate temperatures, more liquid forms and its colour changes from turquoise to beige. Considering that both $\mathrm{NaCl}$ and $\mathrm{WO}_{3}$ have melting points above $800{ }^{\circ} \mathrm{C}$, the liquid formation is a product of the reaction between the two. Especially above $730{ }^{\circ} \mathrm{C}$, as time goes on, no solid $\mathrm{WO}_{3}$ grains remain as a result of the reaction with $\mathrm{NaCl}$ (see ESI Movie $2 \dagger$ ). As reported previously in the literature ${ }^{11}$ and as illustrated later in the text, this reaction has a significant role in both VLS and VSS crystal syntheses.

Once the liquid is fully formed, we cool down the chamber and immediately perform X-ray photoelectron spectroscopy
(XPS) on the solidified liquid to determine its chemical composition. XPS surveys on the solidified liquid show that it is composed of $\mathrm{Na}, \mathrm{O}, \mathrm{W}$ but not $\mathrm{Cl}$. High resolution XPS spectra of $\mathrm{Na} 1 \mathrm{~s}, \mathrm{O} 1 \mathrm{~s}$ and $\mathrm{W} 4 \mathrm{f}$ binding energies exactly match with the values reported for sodium tungstate, $\mathrm{Na}_{2} \mathrm{WO}_{4}$ (Fig. 2(g)). ${ }^{18,19}$ The measured Raman spectrum is in good agreement with the reported spectrum for $\mathrm{Na}_{2} \mathrm{WO}_{4}$ in the literature (Fig. 2(h)). ${ }^{20,21}$ When we consider the chemical reaction between $\mathrm{NaCl}$ and $\mathrm{WO}_{3}$ the second product of the reaction can be $\mathrm{WO}_{2} \mathrm{Cl}_{2} \cdot{ }^{9,11}$

$$
2 \mathrm{WO}_{3}+2 \mathrm{NaCl} \rightarrow \mathrm{WO}_{2} \mathrm{Cl}_{2(\mathrm{~g})}+\mathrm{Na}_{2} \mathrm{WO}_{4(\mathrm{l})}
$$

At above $600{ }^{\circ} \mathrm{C}$, the temperature where we observe the liquid formation, $\mathrm{WO}_{2} \mathrm{Cl}_{2}$ is in the gaseous phase. As the reaction between vapour $\mathrm{NaCl}$ and $\mathrm{WO}_{3}$ begins, $\mathrm{WO}_{2} \mathrm{Cl}_{2}$ forms and leaves the chamber with the carrier gas. This explains why we 
don't observe any $\mathrm{Cl}$ both in XPS and EDX analysis of the later stage molten product. Also, as discussed later in the text, by controlling the presence of $\mathrm{WO}_{2} \mathrm{Cl}_{2}$ in the chamber, we can lead the growth to follow either the VLS or VSS mode.

With the unique abilities we have with our custom-made CVD chamber, we investigated the possible monolayer $\mathrm{WSe}_{2}$ formation routes from both liquid and gaseous intermediate compounds. First, we prepared a mixture of $\mathrm{NaCl}: \mathrm{WO}_{3}$ in a 1:2 weight ratio to study how molten $\mathrm{Na}_{2} \mathrm{WO}_{4}$ forms $\mathrm{WSe}_{2}$ monolayers. A 1:1 molar ratio of $\mathrm{NaCl}: \mathrm{WO}_{3}$ (based on reaction (1)) corresponds to a $1: 4$ weight ratio, yet the salt rich mixture results in liquid $\mathrm{Na}_{2} \mathrm{WO}_{4}$ with a minimum solid content as some salt sublimates during the heat up. A grain of the mixture is placed on an oxidised silicon chip and then heated to $750{ }^{\circ} \mathrm{C}$ in an $\mathrm{Ar}$ environment on the substrate heater to form liquid $\mathrm{Na}_{2} \mathrm{WO}_{4}$. After the liquid formation, we introduced Se. However, this didn't result in $\mathrm{WSe}_{2}$ synthesis and the liquid remained unchanged as the time went on. Although we tried introducing Se vapour at various substrate temperatures ranging from 700 to $900{ }^{\circ} \mathrm{C}$, we didn't observe $\mathrm{WSe}_{2}$ formation. Thus, we deduce that $\mathrm{H}_{2}$ plays an essential role in $\mathrm{WSe}_{2}$ formation.

Although there are numerous reports ${ }^{22-27}$ on the effect of $\mathrm{H}_{2}$ in atomically thin TMDC synthesis, its function in the salt assisted growth is not ubiquitous. To elucidate the role of $\mathrm{H}_{2}$ in monolayer formation, we first tested the sole effect of $\mathrm{H}_{2}$. When we introduce $\mathrm{H}_{2}$ into the molten $\mathrm{Na}_{2} \mathrm{WO}_{4}$, cubic crystals varying in colour from yellow to orange emerge. XPS and Raman measurements show that these crystals are sodium tungsten bronzes $\left(\mathrm{Na}_{x} \mathrm{WO}_{3}, x<1\right)$ of various $\mathrm{Na}$ ratios (see ESI Fig. S9†). ${ }^{28}$ Accordingly, we determine that the temperature at which $\mathrm{H}_{2}$ dosed during the TMDC synthesis is critical to prevent premature reduction of sodium tungstate to sodium tungsten bronze.

Curiously, when we introduce $\mathrm{H}_{2}$ into $\mathrm{Na}_{2} \mathrm{WO}_{4}$ after 20 minutes of Se exposure, we don't observe $\mathrm{WSe}_{2}$ formation. XPS and EDX analyses (Fig. 3(a) and (b)) of the $\mathrm{Na}_{2} \mathrm{WO}_{4}$ liquid exposed to Se for 20 minutes without $\mathrm{H}_{2}$ show that no Se dissolves in $\mathrm{Na}_{2} \mathrm{WO}_{4}$. Even when we add $\mathrm{Se}$ to the $\mathrm{NaCl}: \mathrm{WO}_{3}$ mixture, no Se is detected in the liquid droplets.
We would like to note that when $\mathrm{H}_{2}$ is introduced over hot Se vapour above $300{ }^{\circ} \mathrm{C}, \mathrm{H}_{2}$ reacts with Se to form $\mathrm{H}_{2}$ Se gas. ${ }^{29}$ $\mathrm{H}_{2} \mathrm{Se}$ formation during the synthesis can be imperative in $\mathrm{WSe}_{2}$ growth.

We performed a series of controlled experiments to unravel any possible effect of $\mathrm{H}_{2} \mathrm{Se}$ on $\mathrm{WSe}_{2}$ formation. First, we evacuated the chamber and flushed it with Ar several times. Then, we filled the chamber with a 5:1 ratio of $\mathrm{Ar}: \mathrm{H}_{2}$ until atmospheric pressure was reached and brought the temperature of the Se heater to $350{ }^{\circ} \mathrm{C}$ for Se vapour to react with $\mathrm{H}_{2}$ in the CVD chamber to form $\mathrm{H}_{2} \mathrm{Se}$. We kept the temperature of the substrate heater at $300{ }^{\circ} \mathrm{C}$ to minimize Se condensation on the substrate. After 15 minutes, we shut down the Se heater and ramped up the temperature of the substrate heater to $750{ }^{\circ} \mathrm{C}$. Unreacted Se vapour condenses on the cold chamber walls. As soon as the temperature of the substrate heater went above $650{ }^{\circ} \mathrm{C}$ we started observing the formation of $\mathrm{WSe}_{2}$ monolayers from the forming $\mathrm{Na}_{2} \mathrm{WO}_{4}$ liquid (VLS) as well as at remote positions (VSS) on the substrate where no liquid can be found. As a controlled experiment the Se heater is heated to $350{ }^{\circ} \mathrm{C}$ as before, this time in the absence of $\mathrm{H}_{2}$. After 15 minutes the Se heater is shut down and $5: 1 \mathrm{Ar}: \mathrm{H}_{2}$ is introduced into the chamber and the substrate heater is heated to $750{ }^{\circ} \mathrm{C}$. However, the controlled experiment didn't result in any $\mathrm{WSe}_{2}$ crystal formation. This experiment shows that $\mathrm{H}_{2} \mathrm{Se}$ gas is required to synthesize $\mathrm{WSe}_{2}$ crystals both in VLS and VSS modes. Since selenium has a lower reactivity compared to sulphur, ${ }^{30,31}$ unlike sulphur containing TMDC synthesis, the dependence of $\mathrm{WSe}_{2}$ formation on $\mathrm{H}_{2} \mathrm{Se}$ is not surprising.

All the findings discussed above indicate that for the VLS mode synthesis, $\mathrm{H}_{2}$ Se and $\mathrm{H}_{2}$ gasses react with the liquid intermediate compound $\mathrm{Na}_{2} \mathrm{WO}_{4}$ to form $\mathrm{WSe}_{2}$ following the proposed reaction:

$$
\mathrm{Na}_{2} \mathrm{WO}_{4(\mathrm{l})}+2 \mathrm{H}_{2} \mathrm{Se}_{(\mathrm{g})}+\mathrm{H}_{2(\mathrm{~g})} \rightarrow \mathrm{WSe}_{2(\mathrm{~s})}+3 \mathrm{H}_{2} \mathrm{O}_{(\mathrm{g})}+\mathrm{Na}_{2} \mathrm{O}_{(\mathrm{s})}
$$

Here, $\mathrm{H}_{2}$ is also needed as a reducing agent to reduce $\mathrm{W}^{6+}$ in $\mathrm{Na}_{2} \mathrm{WO}_{4}$ to $\mathrm{W}^{4+}$ in $\mathrm{WSe}_{2}$. For the VSS mode, the gaseous
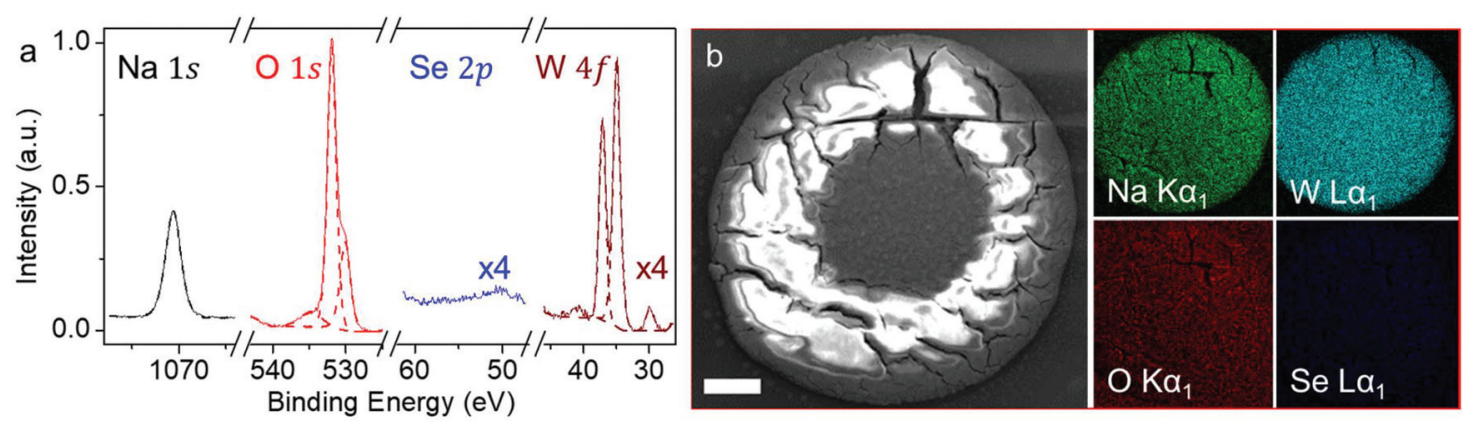

Fig. 3 Effects of Se exposure on $\mathrm{Na}_{2} \mathrm{WO}_{4}$. (a) High resolution XPS spectra of the $\mathrm{Na}_{2} \mathrm{WO}_{4}$ liquid droplet obtained after 20 minutes of exposure to Se. Na $1 s, O$ 1s, Se $2 p$, and W $4 f$ spectra match exactly with $\mathrm{Na}_{2} \mathrm{WO}_{4}$ spectra and no Se $2 p$ peaks exist in the spectrum. (b) SEM image and EDX maps corresponding to the labelled elements are obtained from the solidified $\mathrm{Na}_{2} \mathrm{WO}_{4}$ liquid droplet exposed to Se for 20 minutes. The Se $\mathrm{L} \alpha_{1}$ map shows a faint background as the tail of the $W L \alpha_{1}$ peak extends through Se $L \alpha_{1}$ energy. Scale bar is $20 \mu \mathrm{m}$. 
intermediate product $\mathrm{WO}_{2} \mathrm{Cl}_{2}$ reacts with $\mathrm{H}_{2} \mathrm{Se}$ and $\mathrm{H}_{2}$ to form $\mathrm{WSe}_{2}$ crystals. The chemical reaction of the adsorbed molecules that produce $\mathrm{WSe}_{2}$ can be written as:

$$
\begin{gathered}
\mathrm{WO}_{2} \mathrm{Cl}_{2(\mathrm{ads})}+2 \mathrm{H}_{2} \mathrm{Se}_{(\mathrm{ads})}+\mathrm{H}_{2(\mathrm{~g})} \\
\rightarrow \mathrm{WSe}_{2(\mathrm{~s})}+2 \mathrm{H}_{2} \mathrm{O}_{(\mathrm{g})}+2 \mathrm{HCl}_{(\mathrm{g})}
\end{gathered}
$$

We would like to note that the crystals grow at a much faster rate in the VLS mode compared to the VSS mode. This observation can be described qualitatively as follows: the VSS mode requires gaseous molecules $\left(\mathrm{WO}_{2} \mathrm{Cl}_{2}\right.$ and $\mathrm{H}_{2} \mathrm{Se}$ in the case of $\mathrm{WSe}_{2}$ ) to be adsorbed by the substrate surface and crystal nucleation requires a seed to begin. On the other hand, in VLS mode once the nucleation begins, crystal growth is fuelled by excess supply of constituent precursors and governed by the kinetic effect. ${ }^{32}$ These two proposed reactions are critical to understand the effect of each growth parameter that leads to the $\mathrm{WSe}_{2}$ synthesis.

The ability to control the dominant growth mode could enable directed growth of 2D materials for bottom up device fabrication and high-quality crystal synthesis. When the reaction between the metal-oxide and the salt begins, the VSS precursor is released in the gaseous form and adsorbed by the substrate surface. If there is no $\mathrm{H}_{2}$ and Se present in the chamber, in time, the adsorbed precursor molecules are desorbed from the substrate surface. As the reaction between the salt and the metal-oxide slows down due to consumption of the reactants, partial pressure of the VSS precursor decreases as well. High enough partial pressure of the VLS precursor in the chamber is needed to condense liquid droplets on the target substrate. Several parameters such as separation of the substrate from the precursor heater, carrier gas flow rate and the precursor heater temperature significantly alter the VLS precursor condensation rate. Controlling the temperature and time when $\mathrm{H}_{2}$ and Se are introduced into the chamber allows one to achieve one growth mode over the other. As an example, for $\mathrm{WSe}_{2}$, introducing $\mathrm{H}_{2}$ and Se when the temperature of the precursor heater is around $600{ }^{\circ} \mathrm{C}$ will most dominantly result in the formation of VSS crystals. Delaying the time of $\mathrm{H}_{2}$ and Se by about 10-15 minutes after the temperature of the precursor heater reaches $700{ }^{\circ} \mathrm{C}$ results in the formation of VLS crystals predominantly. This level of control is hard to achieve in a tube furnace based CVD chamber as any change in the precursor temperature will either effect the substrate temperature or the separation between the substrate and the precursor needs to be adjusted at a cost of reducing the amount of precursor that reaches the substrate.

The methodology we presented here can be applied to any other TMDC and their heterostructures that can be synthesized in a CVD chamber. Indeed, we tested the chamber to synthesize other selenium based TMDCs such as $\mathrm{MoSe}_{2}{ }^{27,33-36}$ and its lateral and vertical heterostructures with $\mathrm{WSe}_{2} \cdot{ }^{37}$ Our ability to control the heaters independently enables in situ control of the heterostructure synthesis. We started by observing the heterostructure formation in real time. $10 \mathrm{mg}$ Se and
$10 \mathrm{mg} \mathrm{MoO}_{3}$ are placed on heaters 1 and 3, respectively. Less than a mg, a $1: 10$ mixture of $\mathrm{NaCl}: \mathrm{WO}_{3}$ is placed at a corner of the substrate to enhance the mass transport of $\mathrm{WO}_{2} \mathrm{Cl}_{2}$ (Fig. 4(a)). First, the temperature of the substrate heater is ramped up to $550{ }^{\circ} \mathrm{C}$ while those of heaters 1 and 3 are at 300 and $600{ }^{\circ} \mathrm{C}$, respectively. At this stage, a $7: 1$ mixture of $\mathrm{Ar}: \mathrm{H}_{2}$ is introduced into the chamber to promote the formation of $\mathrm{H}_{2} \mathrm{Se}$ for $\mathrm{MoSe}_{2}$ synthesis. After obtaining several micrometres large $\mathrm{MoSe}_{2}$ monolayers, we shut down heater 3 and the $\mathrm{H}_{2}$ flow. Then, we ramp up the substrate heater to start the $\mathrm{WSe}_{2}$ synthesis. Once the temperature reaches the desired growth temperature, $\mathrm{H}_{2}$ is reintroduced for $\mathrm{WSe}_{2}$ formation until the end of the synthesis.

A series of real time optical microscopy images given in Fig. 4(b) captured at $700{ }^{\circ} \mathrm{C}$ shows the time evolution of the vertical heterostructure. We observed that upon heating, small droplets of $\mathrm{Na}_{2} \mathrm{WO}_{4}$ form at the edge or at the centre of the $\mathrm{MoSe}_{2}$ monolayers, but never in between (see the ESI $\dagger$ ). After the re-introduction of $\mathrm{H}_{2}$, the $\mathrm{WSe}_{2}$ layer nucleates from the liquid precursor. Unlike the monolayer TMDC synthesis, vertical layers form at a very slow rate. Fig. 4(c)-(l) show Raman, PL spectra and AFM height traces of the vertical and the lateral heterostructures. The final temperature of the substrate heater determines whether the heterostructure will form vertically or laterally. Our studies show that substrate temperatures below $725^{\circ} \mathrm{C}$ mostly yield vertical, while above $750{ }^{\circ} \mathrm{C}$ mostly yield lateral heterostructures. This observation can be explained by the kinetic nature of the crystal formation. As the mentioned temperatures are well above the reaction temperature for the $\mathrm{NaCl}: \mathrm{WO}_{3}$ mixture, there are plenty of VLS and VSS precursors available for the crystal nucleation. Thus, substrate temperature determines the heterostructure type rather than the precursor supply unlike the previous reports. ${ }^{38,39}$

In summary, we demonstrated that our custom-made CVD chamber can be used to monitor and control the synthesis routes in real time. We showed that both VSS and VLS routes can be employed to grow selenium based TMDC crystals. In the VSS route, $\mathrm{H}_{2} \mathrm{Se}$ and $\mathrm{H}_{2}$ react with metal-oxychloride to form the monolayers while in the VLS mode a liquid composed of the alkali metal, transition metal and oxygen reacts with $\mathrm{H}_{2} \mathrm{Se}$ and $\mathrm{H}_{2}$ to form the monolayers. We realize that by timing when $\mathrm{H}_{2}$ and Se are introduced, it is possible to control the growth route. Such a degree of control over the synthesis route allowed us to synthesize both lateral and vertical heterostructures of $\mathrm{WSe}_{2}$ and $\mathrm{MoSe}_{2}$ with in situ control. We would like to emphasize that although the intermediate products and the reaction routes may differ among various TMDCs, the methods we present here will still be applicable. Furthermore, the CVD chamber we reported in this article can be modified to investigate the synthesis mechanisms of other materials that utilize a CVD chamber for the growth. Optical observations can be accompanied by other spectroscopic measurement techniques that can be incorporated onto the chamber to provide real time spectroscopic information about the intermediate phases. 

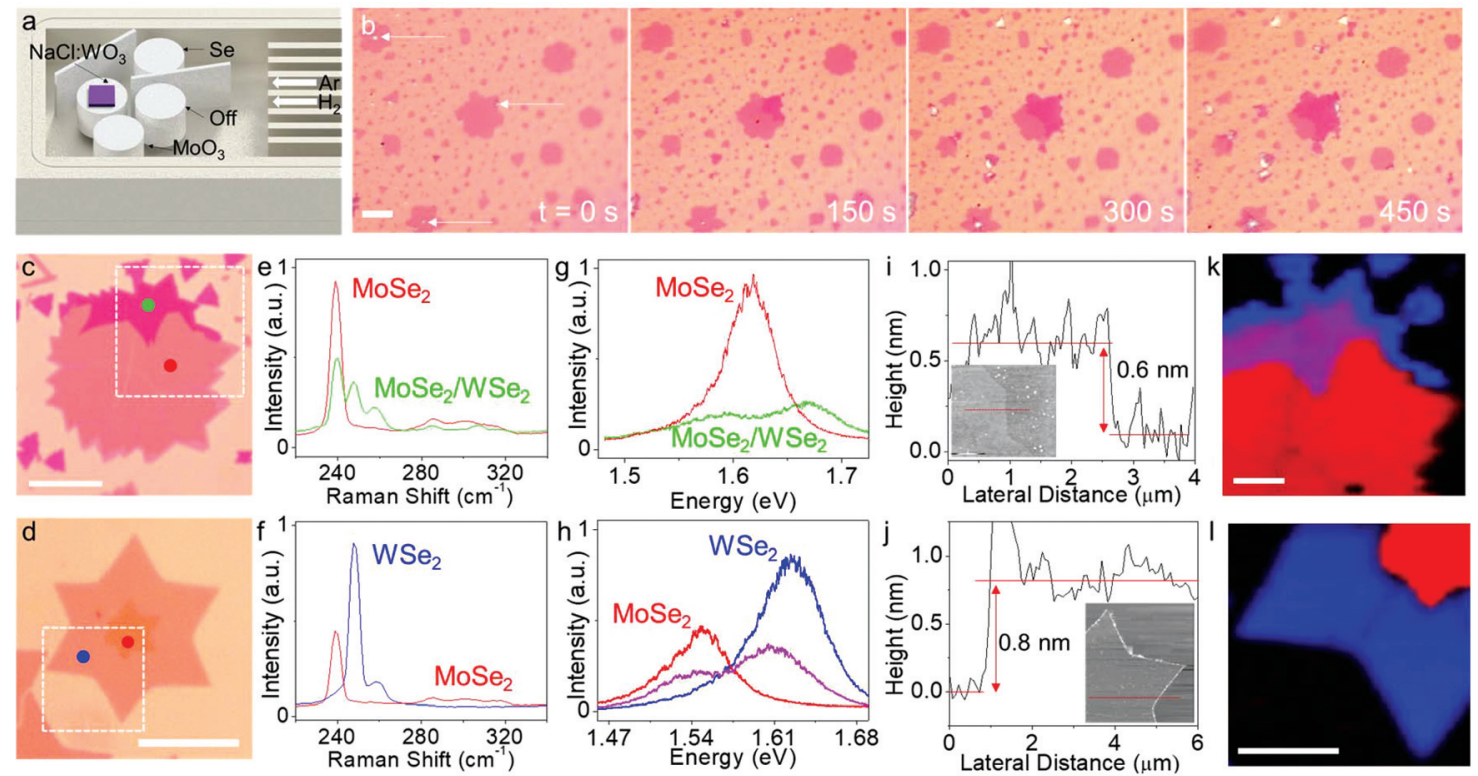

Fig. 4 Real time observation and control of heterostructure synthesis. (a) Schematic shows the configuration of the CVD chamber for the heterostructure synthesis. (b) A series of images obtained at $700{ }^{\circ} \mathrm{C}$ that shows the formation of $\mathrm{WSe}_{2}$ on the $\mathrm{MoSe}_{2}$ monolayer. The white arrows indicate the seeds and how the $\mathrm{WSe}_{2}$ layer forms from it. Scale bar is $10 \mu \mathrm{m}$. (c and d) show optical microscopy images of vertical and lateral heterostructures, respectively. Scale bars are $10 \mu \mathrm{m}$. (e and f) Raman and ( $g$ and h) PL spectra obtained from the locations in (c and d) marked with coloured circles. PL spectra in purple in (h) are obtained from the interface between $\mathrm{MoSe}_{2}$ and $\mathrm{WSe}_{2}$. ( $\mathrm{i}$ and j) AFM height traces obtained along the red dashed line in the inset show the vertical and lateral heterostructures. ( $\mathrm{k}$ and l) Raman intensity maps for the vertical and the lateral heterostructures at $239 \mathrm{~cm}^{-1}$ (red) and $248 \mathrm{~cm}^{-1}$ (blue) obtained from the area marked by white dashed rectangles in (c and d). Purple region in (k) is due to the overlay of the red and blue maps as in this region of the heterostructure, we observe both 239 and $248 \mathrm{~cm}^{-1}$ peaks. Scale bars are $2 \mu \mathrm{m}$.

\section{Methods}

The CVD chamber is machined out of a 6061-aluminium alloy. There are three body pieces that form the chamber: bottom plate, reactor and lid. The bottom plate houses the water circulation channels and the cooling water makes direct contact with the reactor when the two pieces are bolted together. The lid allows easy access to the reactor chamber. There are water jackets within the lid as well. The chamber body temperature is maintained at or near room temperature. A closed-cycle chiller supplies water to the cooling channels embedded within the chamber body and the lid. Outside the chamber, the temperature of the hottest regions remains below $50{ }^{\circ} \mathrm{C}$. The optical port on the lid is a $0.5 \mathrm{~mm}$ thick sapphire disk and it is directly located above the substrate heater. Electrical connections for temperature control are made via hermetically sealed feedthroughs. There are two separate gas inlets, one for Ar and the other for $\mathrm{H}_{2}$ and a single exhaust at the opposite end of the chamber. Gases are dosed through mass flow controllers. The chamber can reach down to $10^{-3} \mathrm{mBar}$ using an oil rotary vane pump. Heater temperatures and gas flow rates are controlled via a LabView software. Detailed pictures of the chamber are given in the ESI. $\dagger$

\section{Author contributions}

TSK conceived the experiments. HRR and TSK designed the CVD chamber and assembled it. HRR and TSK performed the experiments. NM and OÇ helped characterizing the samples. All the authors discussed the results and contributed to the writing of the manuscript.

\section{Conflicts of interest}

There are no conflicts to declare.

\section{Acknowledgements}

This work is supported by Turkish Scientific and Technological Research Council under grant no: 116M226. We would like to thank Engin Can Sürmeli, Koray Yavuz and Ali Sheraz for discussions, Fatih Yaman for his help with the LabView programming, Talha Masood Khan for providing masks for optical lithography and Bülend Ortaç for providing the $\mathrm{MoO}_{3}$ precursor.

\section{References}

1 Y.-H. Lee, X.-Q. Zhang, W. Zhang, M.-T. Chang, C.-T. Lin, K.-D. Chang, Y.-C. Yu, J. T.-W. Wang, C.-S. Chang, L.-J. Li and T.-W. Lin, Adv. Mater., 2012, 24, 2320.

2 J. K. Huang, J. Pu, C. L. Hsu, M. H. Chiu, Z. Y. Juang, Y. H. Chang, W. H. Chang, Y. Iwasa, T. Takenobu and L. J. Li, ACS Nano, 2014, 8, 923. 
3 S. M. Eichfeld, L. Hossain, Y.-C. Lin, A. F. Piasecki, B. Kupp, A. G. Birdwell, R. A. Burke, N. Lu, X. Peng, J. Li, A. Azcatl, S. McDonnell, R. M. Wallace, M. J. Kim, T. S. Mayer, J. M. Redwing and J. A. Robinson, ACS Nano, 2015, 9, 2080.

4 K. Kang, S. Xie, L. Huang, Y. Han, P. Y. Huang, K. F. Mak, C. J. Kim, D. Muller and J. Park, Nature, 2015, 520, 656.

5 Z. Zhang, J. Niu, P. Yang, Y. Gong, Q. Ji, J. Shi, Q. Fang, S. Jiang, H. Li, X. Zhou, L. Gu, X. Wu and Y. Zhang, Adv. Mater., 2017, 29, 1.

6 S. Li, S. Wang, D. M. Tang, W. Zhao, H. Xu, L. Chu, Y. Bando, D. Golberg and G. Eda, Appl. Mater. Today, 2015, 1, 60 .

7 H. Wang, X. Huang, J. Lin, J. Cui, Y. Chen, C. Zhu, F. Liu, Q. Zeng, J. Zhou, P. Yu, X. Wang, H. He, S. H. Tsang, W. Gao, K. Suenaga, F. Ma, C. Yang, L. Lu, T. Yu, E. H. T. Teo, G. Liu and Z. Liu, Nat. Commun., 2017, 8, 394.

8 H. Wang, Y. Chen, M. Duchamp, Q. Zeng, X. Wang, S. H. Tsang, H. Li, L. Jing, T. Yu, E. H. T. Teo and Z. Liu, Adv. Mater., 2018, 30, 1.

9 J. Zhou, J. Lin, X. Huang, Y. Zhou, Y. Chen, J. Xia, H. Wang, Y. Xie, H. Yu, J. Lei, D. Wu, F. Liu, Q. Fu, Q. Zeng, C. H. Hsu, C. Yang, L. Lu, T. Yu, Z. Shen, H. Lin, B. I. Yakobson, Q. Liu, K. Suenaga, G. Liu and Z. Liu, Nature, 2018, 556, 355.

10 Y. Nie, C. Liang, K. Zhang, R. Zhao, S. M. Eichfeld, P.-R. Cha, L. Colombo, J. A. Robinson, R. M. Wallace and K. Cho, 2D Mater., 2016, 3, 025029.

11 S. Li, Y. C. Lin, W. Zhao, J. Wu, Z. Wang, Z. Hu, Y. Shen, D. M. Tang, J. Wang, Q. Zhang, H. Zhu, L. Chu, W. Zhao, C. Liu, Z. Sun, T. Taniguchi, M. Osada, W. Chen, Q. H. Xu, A. T. S. Wee, K. Suenaga, F. Ding and G. Eda, Nat. Mater., 2018, 17, 535.

12 K. Takahashi, K. Yamada, H. Kato, H. Hibino and Y. Homma, Surf. Sci., 2012, 606, 728.

13 Z.-J. Wang, G. Weinberg, Q. Zhang, T. Lunkenbein, A. Klein-Hoffmann, M. Kurnatowska, M. Plodinec, Q. Li, L. Chi, R. Schloegl and M.-G. Willinger, ACS Nano, 2015, 9, 1506.

14 R. S. Weatherup, A. J. Shahani, Z. J. Wang, K. Mingard, A. J. Pollard, M. G. Willinger, R. Schloegl, P. W. Voorhees and S. Hofmann, Nano Lett., 2016, 16, 6196.

15 R. Boston, Z. Schnepp, Y. Nemoto, Y. Sakka and S. R. Hall, Science, 2014, 344, 623.

16 E. Strelcov, A. V. Davydov, U. Lanke, C. Watts and A. Kolmakov, ACS Nano, 2011, 5, 3373.

17 P. K. Chow, R. B. Jacobs-Gedrim, J. Gao, T.-M. Lu, B. Yu, H. Terrones and N. Koratkar, ACS Nano, 2015, 9, 1520.

18 Q. J. Yan, Y. Wang, Y. S. Jin and Y. Chen, Catal. Lett., 1992, 13, 221.
19 G. P. Halada and C. R. Clayton, J. Vac. Sci. Technol., A, 1993, 11, 2342.

20 C. L. Lima, G. D. Saraiva, P. T. C. Freire, M. MacZka, W. Paraguassu, F. F. De Sousa and J. Mendes Filho, J. Raman Spectrosc., 2011, 42, 799.

21 L. L. Y. CHANG and S. SACHDEV, J. Am. Ceram. Soc., 1975, 58, 267.

22 Y. Zhang, Y. Zhang, Q. Ji, J. Ju, H. Yuan, J. Shi, T. Gao, D. Ma, M. Liu, Y. Chen, X. Song, H. Y. Hwang, Y. Cui and Z. Liu, ACS Nano, 2013, 7, 8963.

23 B. Li, Y. Gong, Z. Hu, G. Brunetto, Y. Yang, G. Ye, Z. Zhang, S. Lei, Z. Jin, E. Bianco, X. Zhang, W. Wang, J. Lou, D. S. Galvão, M. Tang, B. I. Yakobson, R. Vajtai and P. M. Ajayan, Angew. Chem., Int. Ed., 2016, 55, 10656.

24 Y. Sheng, H. Tan, X. Wang and J. H. Warner, Chem. Mater., 2017, 29, 4904.

25 H. Wang, D. Zhu, F. Jiang, P. Zhao, H. Wang, Z. Zhang, X. Chen and C. Jin, Nanotechnology, 2018, 29, 314001.

26 Y. Gong, G. Ye, S. Lei, G. Shi, Y. He, J. Lin, X. Zhang, R. Vajtai, S. T. Pantelides, W. Zhou, B. Li and P. M. Ajayan, Adv. Funct. Mater., 2016, 26, 2009.

27 Y. Li, F. Wang, D. Tang, J. Wei, Y. Li, Y. Xing and K. Zhang, Mater. Lett., 2018, 216, 261.

28 P. G. Dickens and M. S. Whittingham, J. Am. Chem. Soc., 1959, 81, 30.

29 B. E. Langer, Ullmann's Encycl. Ind. Chem., 2000, 32, 343.

30 H. J. Reich and R. J. Hondal, ACS Chem. Biol., 2016, 11, 821.

31 T. Wirth, in Compr. Organomet. Chem. III From Fundam. to Appl, ed. M. P. Mingos and R. H. Crabtree, Elsevier Science, 2007, pp. 457-499.

32 Y. Saito and T. Sakiyama, J. Cryst. Growth, 1993, 128, 224.

33 X. Wang, Y. Gong, G. Shi, W. L. Chow, K. Keyshar, G. Ye, R. Vajtai, J. Lou, Z. Liu, E. Ringe, B. K. Tay and P. M. Ajayan, ACS Nano, 2014, 8, 5125.

34 J. C. Shaw, H. Zhou, Y. Chen, N. O. Weiss, Y. Liu, Y. Huang and X. Duan, Nano Res., 2014, 7, 511.

35 Y.-H. Chang, W. Zhang, Y. Zhu, Y. Han, J. Pu, J.-K. Chang, W.-T. Hsu, J.-K. Huang, C.-L. Hsu, M.-H. Chiu, T. Takenobu, H. Li, C.-I. Wu, W.-H. Chang, A. T. S. Wee and L.-J. Li, ACS Nano, 2014, 8, 8582.

36 Y. Zhao, H. Lee, W. Choi, W. Fei and C. J. Lee, RSC Adv., 2017, 7, 27969.

37 P. K. Sahoo, S. Memaran, Y. Xin, L. Balicas and H. R. Gutiérrez, Nature, 2018, 553, 63.

38 Y. Gong, J. Lin, X. Wang, G. Shi, S. Lei, Z. Lin, X. Zou, G. Ye, R. Vajtai, B. I. Yakobson, H. Terrones, M. Terrones, B. K. Tay, J. Lou, S. T. Pantelides, Z. Liu, W. Zhou and P. M. Ajayan, Nat. Mater., 2014, 13, 1135.

39 M.-Y. Li, Y. Shi, C.-C. Cheng, L.-S. Lu, Y.-C. Lin, H.-L. Tang, M.-L. Tsai, C.-W. Chu, K.-H. Wei, J.-H. He, W.-H. Chang, K. Suenaga and L.-J. Li, Science, 2015, 349, 524. 